Research Article

\title{
Developing and Analyzing a Local Gun-Case Database: The Process and Related Issues
}

\begin{abstract}
Allan Y. Jiao
Department of Law \& Justice Studies, Rowan University, 201 Mullica Hill Road, Glassboro, NJ 08028, USA

Correspondence should be addressed to Allan Y. Jiao; jiao@rowan.edu

Received 10 September 2013; Revised 23 December 2013; Accepted 14 January 2014; Published 20 February 2014

Academic Editor: Kim P. Roberts

Copyright (C) 2014 Allan Y. Jiao. This is an open access article distributed under the Creative Commons Attribution License, which permits unrestricted use, distribution, and reproduction in any medium, provided the original work is properly cited.

To maintain public safety and improve system response, a strong need exists for understanding the characteristics of individuals involved in gun crimes, related police activities, and situational/contextual variables surrounding gun incidents. A serious knowledge gap exists, however, in understanding weapon-related offenses at the city level and in how to develop a local guncase database. This paper, which is based on research experiences at an urban police department in USA, describes and analyzes the process and related issues in developing such a database. The study revealed a few critical lessons concerning this process, including those related to communication and cooperation between the police and researchers, quality of data, and importance of a refined dataset for improving local police policies and operations.
\end{abstract}

\section{Introduction}

Weapon-related offenses are a serious concern to the public and police in urban centers across USA. Police organizations have a strong interest in understanding the nature and patterns of gun-related incidents, characteristics of individuals involved, sources and origins of weapons, and related socioeconomic and situational variables in their jurisdictions. A serious knowledge gap exists, however, in understanding weapon-related offenses in general and in local gun crimes in particular. This paper, aimed at understanding the research process for local gun crimes, resulted from a partnership between an urban police department and a regional university.

The original study was focused on exploring the socioeconomic background of individuals involved, routine police responses to gun crimes, and immediate physical environment of gun-related incidents. This was achieved primarily through creating and analyzing a gun-case database. About 300 gun cases were provided by the police and 220 of them were entered into the database. Specific findings of the study, including statistical analyses, were reported and published earlier. But a clear need remains in understanding the process and related issues for developing and analyzing a local guncase database.
The research on a local gun-case database, consistent with the basic elements of scientific research, should include essentially three steps: (1) establishing a conceptual framework, (2) collecting and analyzing the data, and (3) reporting the findings. A description of this process and a discussion of related issues, which are the focus of this paper, are believed to be beneficial to both researchers and practitioners in their future effort to study local gun crimes.

\section{Establishing a Conceptual Framework}

The process of creating and analyzing a local gun-case database for the purpose of understanding gun crimes should begin with establishing an appropriate conceptual framework. Such a framework, which provides guidance for data collection and analysis, should be based on a review of gunrelated literature. A review of such literature for this research revealed three types of publications, those describing the characteristics of gun crimes, those examining the efficacy of gun-related legislations, and those assessing the effectiveness of law enforcement strategies targeting gun violence. Because a local police department usually has only gun-case files in its possession, which include such information as gun incidents, individuals involved, police response, and current 
status, research at the city level should be concentrated on the first and third types of literature, that is, the characteristics of gun crimes, including weapons used and people involved, and police strategies designed to address them.

The review of such literature revealed several conceptual frameworks believed to be relevant to gun studies at the local level. The first involves characteristics of individuals, which can be used to explain gun crimes and weapons used, including types and sources of weapons. The second is premised on the relationship between types of police activities and gun crimes. And the third is grounded in the situational crime prevention perspective, which states that situational and contextual variables influence crimes.

Individual characteristics that are found to influence gun crimes include race $[1,2]$, age $[3,4]$, sex, gang membership [57], drug involvement, and juvenile and adult status [5, 7-15]. Gun crimes range from illegal possession $[16,17]$, unlawfully receiving or transferring a firearm [18], to violent crimes such as robbery and homicide $[17,19]$. Characteristics of weapons include types of weapons used in crimes and sources of weapons such as states, dealers, traffickers, and unregulated markets $[1,4,5,19-22]$.

Police activities defined generally as patrol and investigation strategies can explain the status of gun cases that come to their attention. The literature relevant to this idea typically involves antigun programs designed to address gun violence in various metropolitan areas. Program titles include Operation Ceasefire, Project Exile, Project Safe Neighborhoods, Project Felon, and Project Triggerlock [8, 10, 23-29]. Several other local programs were assessed also in terms of their effect on gun crimes such as the Kansas City Gun Experiment $[30,31]$, community-oriented policing $[20,32]$, and using a case management system [33].

Situational variables have been found to influence gun crimes [1, 15, 20, 34, 35]. Although no study that directly examines the effect of situational variables such as contexts and nature of incidents on gun crimes is available for review at the time of this writing, the situational perspective, grounded in situational prevention [36-38], presents another conceptual framework for understanding the immediate environments of gun incidents. Such factors are important for police officials in their effort to pinpoint types of locations where certain gun crimes tend to occur and thus make informed decisions on deploying officers.

\section{Collecting and Analyzing the Data}

Data collection for gun-related cases at the local level should ideally involve the use of a randomized sample from the pool of all relevant cases, which would allow a general understanding of gun incidents. Such samples are only practical, however, when all related cases contain sufficient data and are available for analysis. In reality, many such cases are either incomplete or under investigation. Which cases are collected ultimately depends on whether the case files contain sufficient information for analysis and whether the police are ready to make them available. For this study, the police provided cases that they believed were relatively complete, including those with known offenders and unknown offenders. The nonrandom nature for this sample was a direct result of the problem of incomplete cases. Had all relevant gun cases been made available for random selection, the sample would result in a substantial number of cases being discarded. As described below, even for cases considered ready for use and provided for analysis by the police, a significant number of them were still dropped from the database due to large amount of missing information. Thus, the nonrandom sampling is not ideal but the only practical procedure for this study.

Regardless of the sampling procedures, cooperation and trust between a local police department and researchers are essential. For this research, the data collection was accomplished through a partnership between an urban police department with roughly 400 officers and a regional university. It is a partnership because the police approached the principal investigator (Investigator hereafter) and provided related files and personnel assistance and the Investigator processed and analyzed the data and wrote the research report. Due to request from the police for keeping this study anonymous, Eastern City is used as the name of the city, the Eastern City Police Department (ECPD) as name of the local police department, and the Eastern City Gun Project (ECGP) as title of this study. The Federal Bureau of Alcohol, Tobacco, and Firearms (BATF) also provided input to this study.

3.1. Codebook. The ECGP began with discussions of gunrelated issues and development of a codebook for coding gun cases. For this purpose, the police liaisons met with the Investigator regularly for a period of six months and provided on-site tours of different sections of Eastern City. Various gun-related variables that fell under the three conceptual frameworks outlined above were brought up, including individuals involved in gun crimes, related police activities, and situations/contexts associated with the gun incidents.

The Investigator was responsible for creating the codebook. The police provided fifty cases initially for brainstorming purposes and starting the process. From these cases, a variable list was created. To ensure that all relevant variables were entered and that the list was complete, numerous meetings were held between ECPD officials and the Investigator to discuss the list. A BATF agent from a local branch office also participated in the discussion. Determining which variables to include was a tedious process due to the complexity of different cases.

The codebook was designed to be comprehensive, guided by the three conceptual frameworks. From the time the original list was developed to the time the codebook was finalized, numerous revisions were made as new information came in and better measurements were found. Three hundred and twenty-seven variables were eventually included in the codebook, organized under ten categories: call information, offense information, suspect information, victim information, witness information, incident area information, weapon information, police response information, drug information, and police investigation information. Suspect, victim, and witness information captured individual characteristics; call, police response, and investigative information provided 
descriptions of related police activities; and offense, incident area, weapon, and drug information contained variables on situations/contexts.

3.2. Data. The ECPD selected the cases on the basis of file completion status. The 300 cases provided to the Investigator represent roughly 15 percent of overall cases for this city, a small number but significant in the sense that files for most of these cases were complete and sufficient for analysis. Several units from the ECPD were involved in pulling the cases, including Criminal Investigation, Records, and Property and Evidence. As the project went on, however, personnel changes or movements occurred within the ECPD, making it difficult at times to maintain communications between the police and the Investigator. Such difficulties resulted in many case files being discarded due to lack of information and reduced the number of cases eventually included in the database.

The case files came in various lengths and sizes, running anywhere from five to over a hundred pages. A great amount of time was spent on coding the case files and entering them into the database. Altogether over 300 gun cases were provided, covering a 7-year period from 2001 to 2007. Of these, 220 cases were found useable and included for analysis and 80 were dropped due to large amount of missing data. Missing data is one of the most serious challenges encountered in this project.

The coding was done mostly by student research assistants under the supervision of the Investigator. Most of the cases were reported in a five-year span from 2002 to 2006, with $26,10,75,61$, and 46 cases, respectively. More occurred in warmer months as 45.9 percent were recorded in April, May, June, and July and 62.3 percent were recorded from March to September. Throughout the coding process, the Investigator reviewed and verified the entered data against the codebook to ensure accuracy. When the coding was completed for all the cases, frequencies for all entered variables were examined to detect any irregularities and address any inaccurate codes.

3.3. Analysis. Analysis of gun cases should be guided by conceptual frameworks and related hypotheses. For this study, the hypotheses are based on the conceptual frameworks reviewed earlier, which represent to a large extent the current research and knowledge of gun incidents at the local level. These hypotheses are focused on three basic ideas; namely, (1) individual characteristics are associated with types of weapon offenses and weapons used; (2) police activities in response to gun incidents influence outcomes of their investigations; and (3) situational/contextual variables are related to types of weapon-related offenses. Since the data includes information on suspects' characteristics, police dispatch and investigative activities, and call districts and crime scene characteristics, the analysis included these as independent variables. Dependent variables include offenses, weapon offenses, weapons/forces used, gun types, gun calibers, pistol types, number of weapons recovered, presence of victims, presence of witnesses, suspect resistance to arrest, presence of drug, suspect status, and case status. Apart from weapons/forces used, gun calibers, pistol types, and number of weapons, all dependent variables were dichotomized. Because of the situational nature of some of these variables such as offenses, gun types, weapons/forces used, presence of drugs, and presence of witnesses, they were also used as situational variables to test their effect on suspect status and case status. Additional variables in the dataset are also relevant to the conceptual frameworks and could be used for analysis, but significant amount of missing information precluded them from analysis.

\section{Reporting the Findings}

The final stage in developing and analyzing a local gun-case database is reporting the findings, which should be guided also by relevant conceptual frameworks and hypotheses. Because of the focus of this paper on the research process and related issues for developing and analyzing a local guncase database, the operationalization of variables, selection of statistical models, and specific analysis results are not included here. A brief summary of the findings is provided below to give readers a sense of the analysis results and to provide the setting for discussing related issues in the following section. As this paper is not written to make any general claims, the purpose here is to discuss these issues using this particular database as an example. The results should not be used to make inferences about gun crimes in urban areas in general.

The analyses of individual characteristics indicate that the younger a suspect is, the more violent the crime tends to be. Older suspects use guns less but they use higher caliber ones when they do. White suspects tend to use guns more often than minority suspects. Local residents tend to commit more serious and substantive weapon offenses than nonlocal residents. Local residents tend to use singleshot weapons including revolvers, shotguns, and rifles more than out-of-state residents. Suspects with prior records are significantly more likely to use pistols and commit violent crimes. Minority suspects tend to be involved in drugs significantly more than white suspects. Cases involving local residents tend to generate more witnesses than cases involving nonlocal residents. And local residents tend to resist arrest more than nonlocal residents. Because of large amount of missing values for other personal background variables such as employment status, occupation, domestic violence record, and gang affiliation, they could not be used for analysis.

The analysis of police activities suggests that types of police investigations, number of police cars/units dispatched, and seizure of a gun are highly significant. Special investigations led to more arrests than general investigations. Cases involving more police cars/units dispatched resulted in more arrests. Cases involving the seizure of a gun as property tend to be closed more often than cases involving no such a seizure. Many other police related variables such as shots fired, shotrelated injuries, fingerprints lifted, weapon test-fired, and warrant issued cannot be analyzed due to significant amount of missing data.

The analyses of situational variables demonstrate that the use of a gun, types of offenses, and scene characteristics 
are statistically significant. More cases involving the use of guns were closed. Gun use was more prevalent in cases involving no victims. Gun use was also highly correlated with violent crimes. More cases involving violent offenses such as assault and robbery remained open than cases involving less violent offenses such as drugs and property crimes. Cases involving possessory offenses resulted in more arrests than cases involving serious crimes. The more public an area, the more substantive the crimes, including suspects using pistols, and the fewer possessory offenses. Although such findings are of interest to the police, many other variables important for gun trace purposes such as state where weapon was registered, city where weapon has record, and serial number defaced or not cannot be entered for analysis once again due to lack of data.

\section{Discussion of Related Issues}

The process for developing and analyzing a weapon-related database is anything but straightforward. From creating the codebook, to collecting the cases, to creating the database, and to analyzing the data, the process is filled with pitfalls and challenges. Expounded below are a few of the thorny issues the Investigator had to contend with, including (1) communications with the police, (2) quality of the data, (3) inadequate analysis, and (4) gap between the original research plan and final outcomes. A brief discussion is also provided on how to address these concerns. It should be noted, however, that these considerations may not be generalizable to all police departments as each agency has its own needs and issues to deal with, which may be quite different.

First, the communication between the Investigator and the ECPD bogged down occasionally in the research process, making it difficult to gather sufficient data and resolve issues on cases already submitted. The ECPD was outstanding in its collaboration during the first year of the project, largely due to the support of the ECPD leadership. Over time, personnel changes took place in the top administration and middle management, along with changes in the mayoral office of the city. The city also experienced a number of major criminal events forcing the police to shift their operational priorities and reshuffle their resources. Some officers originally assigned to the project were consequently reassigned and their replacements were either not immediately available or unfamiliar with the project. The change of direction at the ECPD also led to reduced support and enthusiasm for the project. Although such hurdles did not hinder the Investigator's ability to complete the project eventually, the final research product is of a less desirable quality as a result.

To address these issues, the Investigator had to reintroduce himself, rebuild trust, and reestablish a collaborative working relationship with key police officials. More specifically, the Investigator held phone conversations and personal meetings with the key players, explained the anonymous nature and other ethical principles of scientific research, gave a formal presentation of the research findings to the police management, and discussed the procedures for any publication of the study. Various concerns of the police administration such as liability issues were also addressed during these meetings. It is believed that a committed attitude and a professional approach on the part of the researchers are essential to make any new progress after a communication blockage.

Second, quality of the data had been a constant issue. Many cases did not contain sufficient information for analysis. These include, for example, victims' race, types of drug offenses, states where guns were registered, suspect employment records, many variables related to second, third, and/or fourth suspects, and shot-related variables. Two primary factors, lack of complete cases available for analysis and difficulty in locating relevant information by the police, could have contributed to the large amount of missing data. The lack of complete cases and difficulty in obtaining the variable information most likely had resulted from unclear procedural requirement and low level of collaboration among different law enforcement agencies. In the coding process, for example, it was found that the serial number was sometimes eliminated or defaced. When this happened, the BATF trace reports should have been consulted, but this had not always been done.

The police and the Investigator understood that, ideally, each firearm seized should be entered into the database and then traced by the BATF back to its original owner. That owner could then be contacted and a determination could be made as to how the weapon ended up in the street of the city. If a pattern develops, appropriate enforcement actions could be taken. In reality, however, not every gun was submitted for tracing by the BATF or the state police and many guncase files suffered from missing or insufficient information. The police intended to correct such deficiencies in the future, but for the time being the related variables in the dataset have either no values or contain many missing values.

Third, the poor quality of the data means that only certain analyses as those described above were conducted, while many others were either done superficially or not done at all. The effects of the illicit drug market, an increased access to and use of guns by juveniles $[3,39]$, and the sale and distribution of firearms on gun violence, for example, could not be analyzed. The differences between juveniles and adults $[5,15]$ could not be determined in terms of their access to and use of guns. The relationship between types of drug offenses and weapon offenses could not be established. The relationship between offenders and victims $[4,40]$ could not be tested. And it was impossible to analyze differences between male and female offenders [4], gang membership [5$7]$, and attitudes and mental health conditions of the offenders [22, 41-43].

Also due to perhaps the large number of missing values, some analyses associated with the three conceptual perspectives and related hypotheses yielded only insignificant results. Analyses of individual characteristics such as suspect sex and police activities such as original call to action, lifting of fingerprints, warrants issued, outstanding warrants, and number of weapons recovered show no significant effect on 
types of offenses committed, types of weapon violations, makes/types of pistols, suspects' resistance to arrest, presence of drugs, suspect status, and case status.

Several measures may be taken to reduce cases with missing values and improve the quality of data. The police administration can give more consistent instructions to police officers and require that they fill out all listed items in their guncase processing forms. The current forms should be expanded to include more relevant data. Training should be provided to officers on how to locate and obtain missing information to ensure that all blanks that can be filled out are filled. For example, officers should be trained on how to obtain gun trace information from the state police and/or the BATF. Better coordination with other law enforcement agencies would also be necessary whenever gun-related information exists elsewhere. All these measures may prove challenging to the police because of the time and resources required and officer reluctance to do extra paperwork. But if effective police operation is the goal, more information about gun cases is essential and police management needs to set the tone about the importance of gathering all relevant information.

Fourth, a significant gap between the original research plan and final outcomes emerged at the end of the research. The ECPD officials originally envisioned that the analysis of this database would lead to an improved understanding of not only individuals and/or groups involved in the illegal use of weapons but also the paths the firearms have traveled before reaching the city, including original purchasers and vendors and locations where the weapons had changed hands. It was expected that this data, like some previous research [34], would pinpoint the states where the weapons came from. While this study does suggest a significant difference between local and nonlocal residents in terms of offenses they committed and behaviors they displayed toward the authorities, it does not indicate where the weapons were purchased and how many individuals were involved before the weapons were seized in the city.

The analysis results failed to meet this important expectation of the ECPD due to large amount of missing information for related variables. The solutions to this problem would be similar to those suggested above for improving the quality of data, including better instructions and training of officers, more extensive gun-case processing forms that include gun trace information, better coordination and collaboration with other law enforcement agencies, and stronger emphasis on collecting all relevant data from police management. Given that police officers already inundated with paperwork may fail to see how a complete database may actually help them, police management should make it clear that gun crime is a serious offense and a police priority and that a complete database would allow the police to manage their resources according to patterns uncovered from the data and thereby prevent more future gun crimes from occurring. With a more accurate understanding of the nature of gun incidents, officers would be able to target this problem more effectively instead of responding to frequent gun calls without ever having an opportunity to address their root causes.

\section{Conclusions}

The amount of research that has delved into gun cases at the local level is rather limited. The ECGP approached gun crimes from three different perspectives, that is, individual characteristics, routine police activities, and situational variables surrounding gun-related incidents, which provide a comprehensive conceptual framework for studying local gun crimes. Coupled with this framework, this paper provides a detailed description of the process and related issues in developing and analyzing a local gun-case database.

While it is the goal of gun studies to understand types of individuals and demographics of those prone to carrying and using firearms and shed light on effects of police activities and situational variables on gun-related offenses, it is critical to appreciate also the process for creating and analyzing a local gun-case database. The analyses of individual characteristics provide insight into individuals involved in gun crimes and potential relationships between offenders and victims. The understanding of police operational and situational variables highlights the dynamics of gun incidents and their investigations as influenced by routine police activities and their immediate surroundings. But all such knowledge could deviate significantly from the truth if the process for developing a local gun-case database is not well planned and the eventual database itself is substandard.

Whether the process for developing a gun-case database is well designed and the database is of high quality determines whether the analysis results can be relied upon for related law enforcement policies and operations. Such data should only be used for training and deployment purposes after the police have committed themselves to a stringent research process and a high-quality database has been developed as a result.

This research revealed a few important lessons concerning the process for developing and analyzing a local guncase database. It demonstrates essentially that consistent communication and cooperation between the police and researcher(s) must be maintained in order to gather sufficient data and resolve issues on cases already collected. The quality of the data can be improved only if the police are able to raise their file-keeping standards by requiring, for example, that certain basic, critical variable information, if ever available or obtainable, be located and entered into each of their case files. And only a refined dataset will allow the police to develop valuable information necessary for training and deployment purposes.

Future gun research, therefore, should be focused on developing a comprehensive, high-quality database. Such a database would lead to a more accurate and detailed understanding of individuals involved in gun crimes, effectiveness of police activities, and influence of situational and contextual variables at the local level. This means that both the quality and quantity of case files from a local police department must be increased and weaknesses associated with missing variables and small sample size be minimized. While the measures taken to achieve this goal are specific to each individual research project, they should invariably include maintaining frequent communication, building trust, and upholding a high standard in database development. 


\section{Conflict of Interests}

The author declares that there is no conflict of interests regarding the publication of this paper.

\section{Acknowledgments}

This research was partially funded by Rowan University. The author wishes to thank Professor Stanley Yeldell and ten student research assistants for their assistance in completing a part of the research. Comments from two anonymous reviewers are also appreciated, which have helped the author in revising and improving the paper.

\section{References}

[1] P. J. Cook and J. Ludwig, Guns in America: National Survey on Private Ownership and Use of Firearms. Research in Brief, National Institute of Justice, Washington, DC, USA, 1997.

[2] R. Martinez Jr., A. L. Nielsen, and R. Rosenfeld, "Firearm use, injury, and lethality in assaultive violences: an examination of ethnic differences," Homicide Studies, vol. 9, no. 2, pp. 83-108, 2005.

[3] L. A. Greenfeld and M. W. Zawitz, Weapons Offenses and Offenders, Bureau of Justice Statistics Selected Findings, Washington, DC, USA, 1995.

[4] National Institute of Justice (NIJ), Reducing Gun Violence: Community Problem Solving in Atlanta, Department of Justice, Washington, DC, USA, 2006.

[5] S. H. Decker, S. Pennell, and A. Caldwell, Illegal Firearms: Access and Use By Arrestees. National Institute of Justice Research in Brief, National Institute of Justice, Office of Justice Programs, USA Department of Justice, Washington, DC, USA, 1997.

[6] T. P. Thornberry, M. D. Krohn, A. J. Lizotte, C. A. Smith, and K. Tobin, Gangs and Delinquency in Developmental Perspective, Cambridge University Press, New York, NY, USA, 2003.

[7] A. M. Watkins, B. M. Huebner, and S. H. Decker, "Patterns of gun acquisition, carrying, and use among juvenile and adult arrestees: evidence from a high-crime city," Justice Quarterly, vol. 25, no. 4, pp. 674-700, 2008.

[8] S. Allis, "How to start a ceasefire: learning from Boston," Time, vol. 150, no. 3, 1997.

[9] Bureau of Alcohol, Tobacco, and Firearms (BATF), Crime Gun Trace Analysis Report: The Illegal Youth Firearms Market in St. Louis, Missouri, Department of the Treasury, Washington, DC, USA, 1999.

[10] A. A. Braga, D. M. Kennedy, E. J. Waring, and A. M. Piehl, "Problem-oriented policing, deterrence, and youth violence: an evaluation of Boston's operation ceasefire," Journal of Research in Crime and Delinquency, vol. 38, no. 3, pp. 195-225, 2001.

[11] S. H. Decker and R. Ruddell, "Kids and assault weapons: social problem or social construction?" Criminal Justice Review, vol. 30, no. 1, pp. 45-63, 2005.

[12] C. W. Harlow, Firearm Use by Offenders: Survey of Inmates in State and Federal Correctional Facilities, Bureau of Justice Statistics, Washington, DC, USA, 2001.

[13] R. Ruddell, "Using the NIJ threat level scale to evaluate the capacity for lethalithy of juvenile firearm," in Proceedings of the Midwestern Criminal Justice Association Annual Meeting, Chicago, Ill, USA, October 2000.
[14] R. Ruddell and G. L. Mays, "Examining the arsenalof juvenile gunslingers: trends and policy implications," Crime and Delinquency, vol. 49, no. 2, pp. 231-252, 2003.

[15] M. W. Zawitz, Firearms, Crime, and Criminal Justice: Guns Used in Crime, Bureau of Justice Statistics, U.S. Department of Justice, Washington, DC, USA, 1995.

[16] D. M. Kennedy, A. M. Piehl, and A. A. Braga, "Youth gun violence in Boston: gun markets, serious youth offenders, and a use reduction strategy," Law and Contemporary Problems, vol. 59, pp. 147-196, 1996.

[17] G. L. Pierce, L. Briggs, and D. A. Carlson, The Identification of Patterns in Firearms Trafficking: Implications for Focused Enforcement Strategies, Department of Treasury, Washington, DC, USA, 1996.

[18] J. Scalia, "Federal Firearm Offenders, 1992-1998," Bureau of Justice Statistics Special Report, Office of Justice Program, Bureau of Justice Statistics, U.S. Department of Justice, Washington, DC, USA, 2000.

[19] G. Kleck, Point Blank: Guns and Violence in America, Aldine Transaction, New Brunswick, NJ, USA, 2005.

[20] Bureau of Alcohol, Tobacco and Firearms (BATF), Crime Gun Trace Reports (2000), National Report, the ATF Youth Crime Gun Interdiction Initiative, Department of the Treasury, Washington, DC, USA, 2002.

[21] D. A. Manson and D. K. Gillard, Presale Handgun Checks: A National Estimate, 1996, Bureau of Justice Statistics Bulletin, Department of Justice, Office of Justice Programs, Washington, DC, USA, 1997.

[22] J. F. Sheley and J. D. Wright, In the Line of Fire: Youth, Guns, and Violence in Urban America, Aldine de Gruyter, New York, NY, USA, 1995.

[23] G. L. Carter, Gun Control in the United States: A Reference Handbook, ABC-CLIO, Denver, Colo, USA, 2006.

[24] D. M. Kennedy, "We can make Boston safe again," The Boston Globe, 2002.

[25] D. M. Kennedy, A. A. Braga, A. M. Piehl, and E. J. Waring, Reducing Gun Violence: The Boston Gun Project, National Institute of Justice, Washington, DC, USA, 2001.

[26] T. C. O'Shea, "Getting the deterrence message out: the project safe neighborhoods public-private partnership," Police Quarterly, vol. 10, no. 3, pp. 288-307, 2007.

[27] B. K. Payne and R. R. Gainey, "Guns, offense type, and Virginia Exile: should gun reduction policies focus on specific offenses?" Criminal Justice Policy Review, vol. 19, no. 2, pp. 181-195, 2008.

[28] S. Raphael and J. Ludwig, "Prison sentence enhancements: the case of project exile," in Evaluating Gun Policy: Effects on Crime and Violence, J. Ludwig and P. J. Cook, Eds., pp. 251-276, Brookings Institution Press, Washington, DC, USA, 2003.

[29] G. E. Tita, K. J. Riley, G. Ridgeway, and P. W. Greenwood, Reducing Gun Violence: Operation Ceasefire in Los Angeles, Office of Justice Programs, National Institute of Justice, Washington, DC, USA, 2005.

[30] L. W. Sherman, "Reducing gun violence: what works, what doesn't, what's promising," Criminal Justice, vol. 1, no. 1, pp. 1125, 2001.

[31] L. W. Sherman, J. W. Shaw, and D. P. Rogan, “The Kansas City gun experiment. Research in brief," NCJ 150855, National Institute of Justice, Washington, DC, USA, 1995.

[32] J. Cohen and J. Ludwig, "Policing crime guns," in Evaluating Gun Policy: Effects on Crime and Violence, J. Ludwig and P. J. Cook, Eds., pp. 217-239, Brookings Institution Press, Washington, DC, USA, 2003. 
[33] B. Scales and J. Baker, Seattle's Effective Strategy for Prosecuting Juvenile Firearm Offenders. Juvenile Justice Bulletin, U.S. Department of Justice, Washington, DC, USA, 2000.

[34] F. Kaplan, "Jury finds gun firms negligent," The Boston Globe, 1999.

[35] J. Sugarmann and K. Rand, Cease Fire: A Comprehensive Strategy to Reduce Firearms Violence, Violence Policy Center, Washington, DC, USA, 1994.

[36] P. J. Brantingham and P. L. Brantingham, Environmental Criminology, Waveland Press, Prospect Heights, Ill, USA, 2nd edition, 1991.

[37] R. V. Clarke, Situational Crime Prevention: Successful Case Studies, Harrow and Heston, Albany, NY, USA, 1992.

[38] P. Mayhew, R. V. Clarke, A. Sturman, and J. M. Hough, Crime as Opportunity, HMSO, London, UK, 1976.

[39] Office of Juvenile Justice and Delinquency Prevention, Reducing Youth Gun Violence: An Overview of Programs and Initiatives, U.S. Department of Justice, Office of Justice Programs, Washington, DC, USA, 1996.

[40] K. M. Heide and T. A. Petee, "Weapons used by juveniles and adult offenders in U.S. parricide cases," Journal of Interpersonal Violence, vol. 22, no. 11, pp. 1400-1414, 2007.

[41] T. Lewis, R. Leeb, J. Kotch et al., "Maltreatment history and weapon carrying among early adolescents," Child Maltreatment, vol. 12, no. 3, pp. 259-267, 2007.

[42] J. H. Goldberg, "Worldview of high-risk juvenile delinquents: relationship to decisions to shoot," Criminal Justice and Behavior, vol. 34, no. 6, pp. 846-861, 2007.

[43] H. Haas and M. Killias, "The role of weapons in violent acts: some results of a Swiss national cohort study," Journal of Interpersonal Violence, vol. 17, no. 1, pp. 14-32, 2002. 

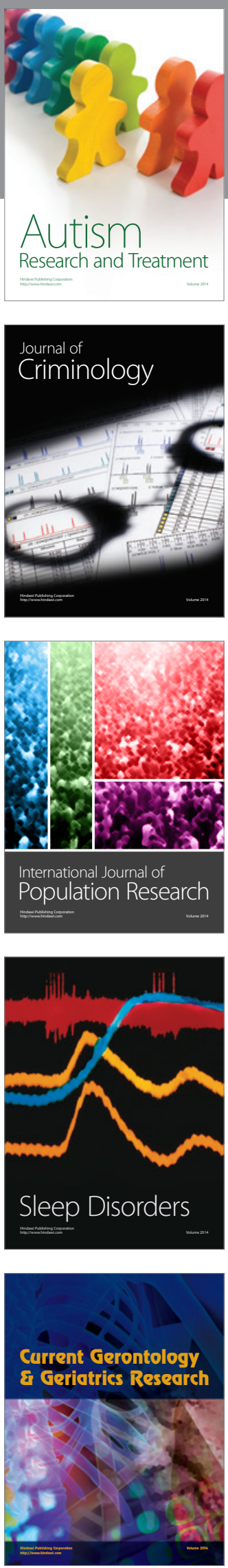
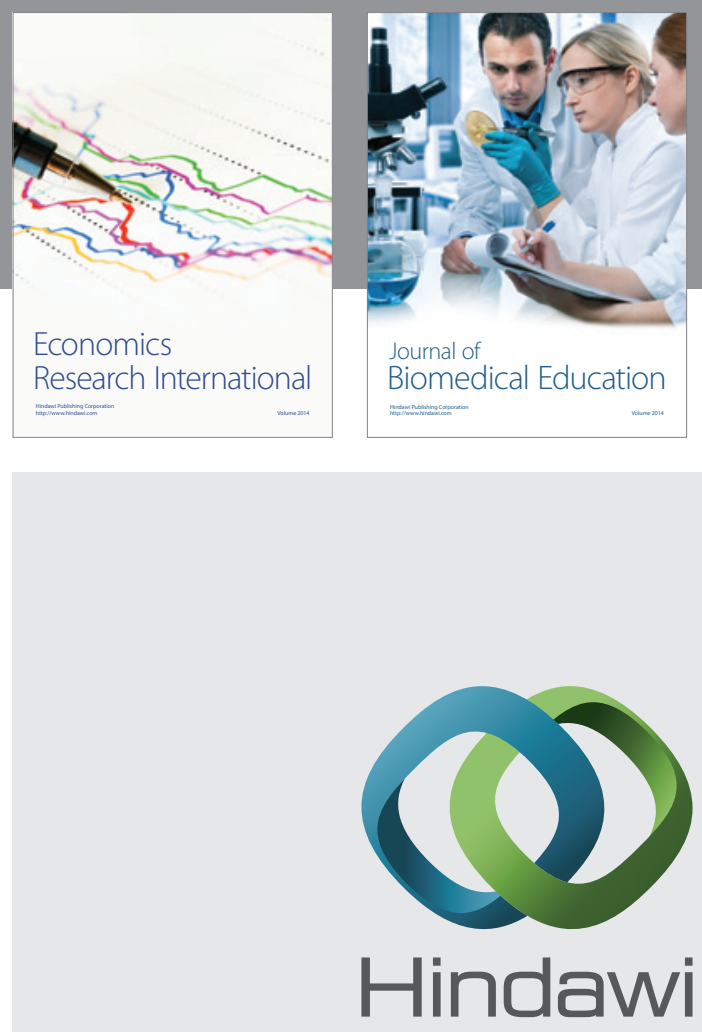

Submit your manuscripts at

http://www.hindawi.com
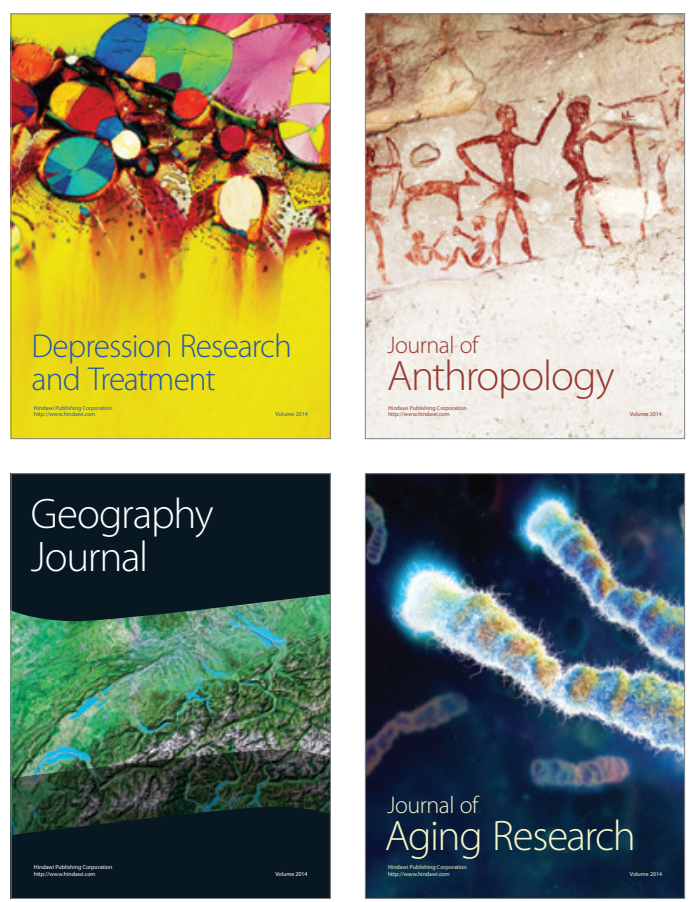
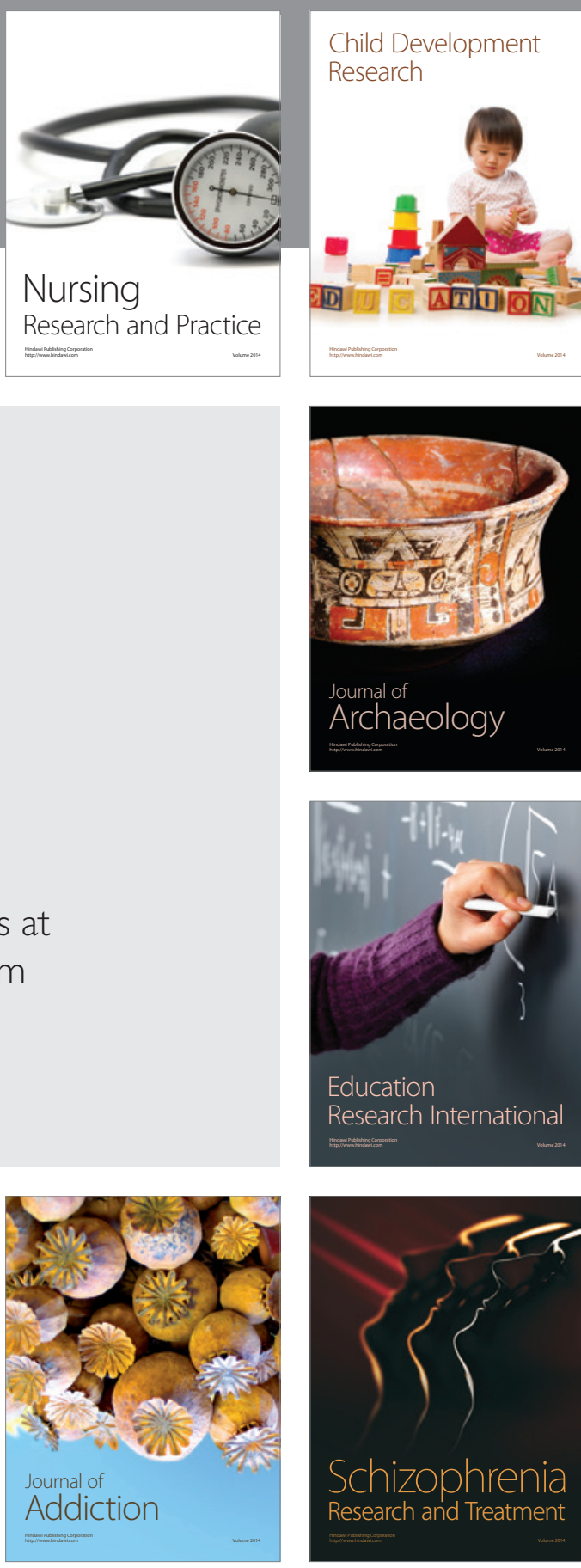

(D)
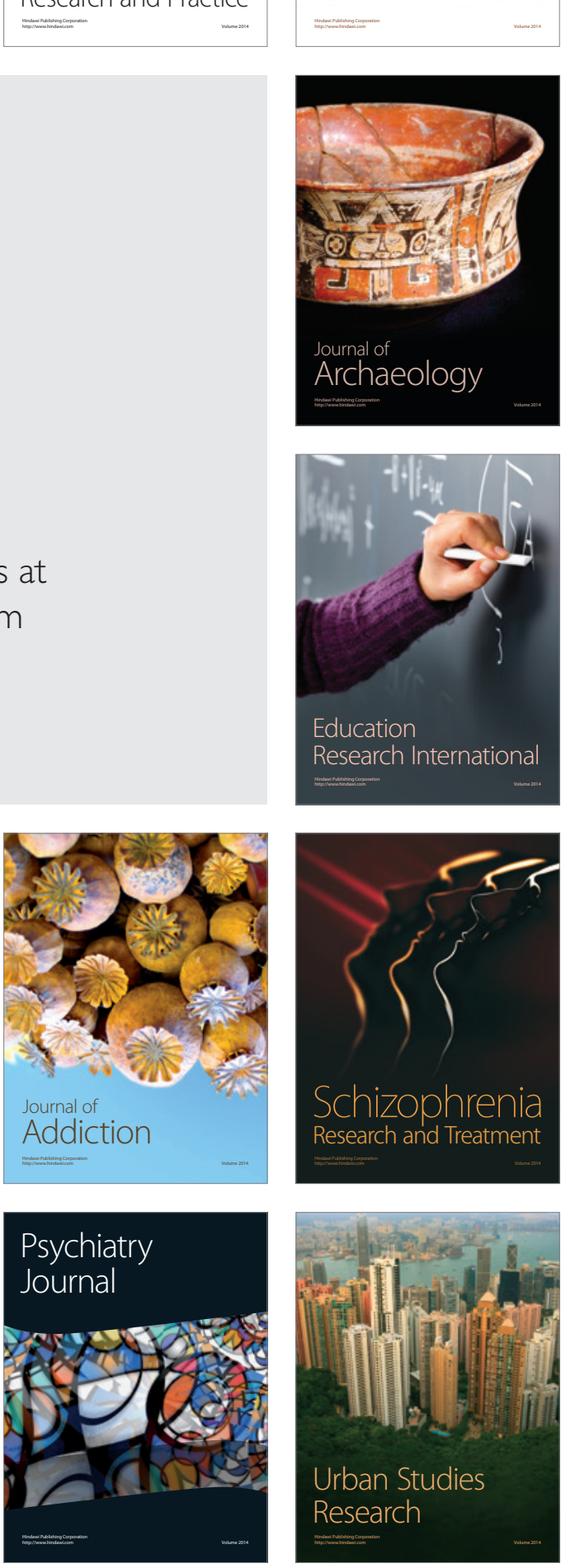